TITLE:

\title{
Process integration of ethanol production from Japanese beech as treated with hot-compressed water followed by enzymatic treatment
}

\section{$\operatorname{AUTHOR}(\mathrm{S}):$}

Nakata, Toshiki; Miyafuji, Hisashi; Saka, Shiro

\section{CITATION:}

Nakata, Toshiki ... [et al]. Process integration of ethanol production from Japanese beech as treated with hot-compressed water followed by enzymatic treatment. Journal of Wood Science 2009, 55(4): 295-301

ISSUE DATE:

2009-08

URL:

http://hdl.handle.net/2433/87472

\section{RIGHT:}

c The Japan Wood Research Society 2009.; この論文は出版社版であり ません。引用の際には出版社版をご確認ご利用ください。; This is not the published version. Please cite only the published version. 
Original article

Process integration of ethanol production from Japanese beech as treated with hot-compressed water followed by enzymatic treatment

Toshiki Nakata $•$ Hisashi Miyafuji $•$ Shiro Saka

Key words ethanol production $\cdot$ hot-compressed water treatment $\cdot$ enzymatic treatment $\cdot$ process integration

T. Nakata • H. Miyafuji • S. Saka ( )

Department of Socio-Environmental Energy Science, Graduate School of Energy Science, Kyoto University, Kyoto 606-8501, Japan

Tel. +81-75-753-4736: Fax +81-75-753-4736

e-mail: saka@energy.kyoto-u.ac.jp 
Abstract

Ethanol was produced from the hydrolysate collected as a water-soluble (WS) portion and a residue after hot-compressed water (HCW) treatment of Japanese beech with and without fractionation. Simultaneous saccharification with $\beta$-xylosidase and isomerization with xylose isomerase followed by fermentation with Saccharomyces cerevisiae were applied to the ethanol production from the WS portion, and simultaneous saccharification with cellulase and fermentation with S. cerevisiae was applied to that from the residue. Integration of the processes for the WS portion and the residue was investigated to improve the conversion efficiency throughout the whole process. The ethanol yield in the integrated process without fractionation was comparable with that for the process with fractionation. Ethanol yields were improved for both of the processes by modifying the operation pattern in which cellulase was added prior to fermentation of the residue. 
Introduction

Ethanol production from lignocellulosics with hydrolytic enzymes and microorganisms requires an effective pretreatment to optimize the subsequent enzymatic and microbial processes. Two portions are obtained after centrifugation and filtration of the hydrolysate: a water-soluble (WS) portion that is rich in hemicellulose-derived pentosan, and a residue that is rich in cellulose fiber. Hot-compressed water (HCW) treatment is among promising pretreatments, and has the potential to recover most of the pentosan in the WS portion and generate reactive fiber in the residue. ${ }^{1}$

This reactive cellulose fiber is effectively converted into glucose with cellulolytic enzymes, because degradation of glucose is minimized in the HCW treatment. ${ }^{2}$ In addition, hemicellulose degradation and lignin transformation due to high temperatures increase the potential of cellulose hydrolysis. ${ }^{1}$ Simultaneous enzymatic saccharification and fermentation (SSF) is an effective process for ethanol production from the cellulose in the hydrolysate. ${ }^{3,4}$ In SSF, the concentration of glucose is constantly kept low because the microorganism ferments it to ethanol as soon as it is liberated from the residue, ${ }^{5}$ and inhibition of glucose on cellulase is mitigated. However, a conditions compromise must be reached for $\mathrm{pH}$ and temperature between the enzyme and microorganism.

For the WS portion, on the other hand, further conversion is necessary to recover monosaccharides because most of the pentosans are recovered in the form of oligosaccharides in the HCW treatment. In our previous study regarding an enzymatic saccharification of the WS portion after the HCW treatment of Japanese beech, xylooligosaccharides in the WS portion were found to be converted into xylose with $\beta$-xylosidase. ${ }^{6}$ Subsequently, enzymatic isomerization using xylose isomerase can be applied to the WS portion to convert xylose into its ketoisomer, xylulose using xylose isomerase which can be utilized by a yeast, Saccharomyces cerevisiae to produce ethanol. Integration of saccharification and isomerization, or isomerization and fermentation was found to enhance ethanol production from the WS portion, and the former process was found to be more 
effective. $^{7}$

In this study, ethanol production from the WS portion and the residue with and without fractionation was performed. Simultaneous saccharification and isomerization followed by fermentation was applied to produce ethanol from the WS portion based on the results obtained in the previous study as mentioned above, whereas SSF was applied to produce ethanol from the residue. Each of the processes from the WS portion and the residue was integrated to investigate the effect of integration of these two processes on ethanol production. Modification of the operation pattern was also made to improve the ethanol yields.

Experimental

Materials and chemicals

Japanese beech (Fagus crenata) was subjected to HCW treatment. Wood chips of Japanese beech were milled into flours passing through 80 mesh to be used as raw materials. Glucose and xylose as standard monosaccharides were purchased from Nacalai Tesque, Inc. (Kyoto, Japan) and xylulose from Sigma-Aldrich (St.Louis, MO, USA). Distilled water and $97 \%$ sulfuric acid in high performance liquid chromatography (HPLC) grade were purchased from Nacalai Tesque, Inc. (Kyoto, Japan).

HCW treatments

The HCW treatment of Japanese beech was conducted in a batch reactor at $240^{\circ} \mathrm{C}$ for $90 \mathrm{~s}$ as described elsewhere ${ }^{8,9}$ Fractionation of the WS portion and the residue after the HCW treatment was made by centrifugation and filtration with a $0.45-\mu \mathrm{m}$ membrane. The residue was washed several times with distilled water and dried in air until constant weight was attained. 
Enzymes

Cellulase (Celluclast 1.5L) was purchased from Novozymes A/S (Bagsvaerd, Denmark). According to the manufacturer's descriptions, Celluclast 1.5L was purified from Trichoderma reesei ATCC 26921, its activity was 797 endoglucanase units (EGU) per gram in $1.2 \mathrm{~g} \mathrm{ml}^{-1}$ enzyme solution, representing 956.4 EGU ml ${ }^{-1}$ enzyme solution. Endo-glucanase activity was measured in EGU was measured in relation to a reduction in viscosity of carboxymethyl cellulose substrate treated with cellulase at pH 6.0 at $40^{\circ} \mathrm{C}$.

Cellobiase, Novozyme 188 was also purchased from Novozymes A/S (Bagsvaerd, Denmark). According to the manufacturer's descriptions, Novozyme 188 was purified from Aspergillus niger, its activity was 277 cellobiase units (CBU) per gram, supplied in an enzyme solution. One cellobiase unit (CBU) was defined as the amount of enzyme that releases $2 \mu$ mol glucose per minute with cellobiose as substrate at $\mathrm{pH} 5.0$ at $40^{\circ} \mathrm{C}$.

$\beta$-Xylosidase was purchased from MP Biomedicals, Inc. (Irvine, CA, USA). According to the manufacturer's descriptions, $\beta$-xylosidase was purified from Trichoderma viride; its activity was 5 $\mathrm{U} \mathrm{mg}^{-1}$ solid. One unit of $\beta$-xylosidase was defined as the amount of enzyme required to liberate $1 \mu$ mol of $p$-nitrophenol from $p$-nitrophenyl- $\alpha$-D-xylopyranoside per minute at $\mathrm{pH} 4.0$ at $37^{\circ} \mathrm{C}$. Five units of $\beta$-xylosidase solid was dispersed in $0.1 \mathrm{M}$ acetate buffer to be adjusted to $2.9 \mathrm{U} \mathrm{ml}^{-1}$ and supplied as enzyme solution.

Xylose isomerase (Sweetzyme T) was purchased from Novozymes A/S. According to the manufacturer's descriptions, Sweetzyme T was an immobilized xylose isomerase produced from Streptomyces murinus; its activity was $350 \mathrm{U} \mathrm{g}^{-1}$. One unit was defined as the amount of enzyme that converts glucose to fructose at an initial rate of $1 \mu \mathrm{mol}$ per minute at $\mathrm{pH} 7.5$ at $60^{\circ} \mathrm{C}$. 
Fermentation

The yeast strain used was Saccharomyces cerevisiae (NBRC 0203). Inoculum was cultivated in a medium containing $10 \mathrm{~g} \mathrm{~L}^{-1}$ glucose, $3 \mathrm{~g} \mathrm{~L}^{-1}$ yeast extract, $3 \mathrm{~g} \mathrm{~L}^{-1}$ malt extract and $5 \mathrm{~g} / \mathrm{L}$ peptone for $24 \mathrm{~h}$ at $28^{\circ} \mathrm{C}$ with shaking at $120 \mathrm{rpm}$. A nutrient broth was prepared containing $120 \mathrm{~g} \mathrm{~L}^{-1}$ yeast extract, $120 \mathrm{~g} \mathrm{~L}^{-1}$ malt extract and $200 \mathrm{~g} \mathrm{~L}^{-1}$ peptone. The medium was sterilized by autoclaving at $121^{\circ} \mathrm{C}$ for $20 \mathrm{~min}$. The fermentation volume was $3 \mathrm{ml}$ containing $2.775 \mathrm{ml}$ of the WS portion or distilled water, $0.15 \mathrm{ml}$ of the inoculums and $0.075 \mathrm{ml}$ of the nutrient broth.

Simultaneous saccharification and fermentation of the residue

SSF was carried out on the residue with cellulase supplemented with cellobiase and the fermentation medium without agitation in a 7-ml glass bottle equipped with a cannula as an exhaust of carbon dioxide. The initial substrate concentration was adjusted to $10 \mathrm{~g} \mathrm{~L}^{-1}$ by adding $3 \mathrm{ml}$ of the fermentation medium containing the WS portion or distilled water. Cellulase was loaded at $9.56 \mathrm{U} \mathrm{ml}^{-1}$ and cellobiase was supplemented at $1.39 \mathrm{U} \mathrm{ml}^{-1}$. The $\mathrm{pH}$ was adjusted to 5.0 using solid $\mathrm{Ca}(\mathrm{OH})_{2}$ and $\mathrm{HCl}$ solution, and the temperature was set at $30^{\circ} \mathrm{C}$ or $40^{\circ} \mathrm{C}$.

Simultaneous saccharification and isomerization of WS portion

Simultaneous saccharification and isomerization was carried out on the WS portion with $\beta$-xylosidase and xylose isomerase without agitation in a 6-ml glass vial containing $3 \mathrm{ml}$ of the WS portion. To the WS portion after HCW treatment, $\beta$-xylosidase was loaded at $0.03 \mathrm{U} \mathrm{ml}^{-1}$. Xylose isomerase was loaded at $12 \mathrm{U} \mathrm{ml}^{-1}$. The $\mathrm{pH}$ was adjusted to 6.0 using solid $\mathrm{Ca}(\mathrm{OH})_{2}$ and $\mathrm{HCl}$ solution, and the temperature was set at $50^{\circ} \mathrm{C}$. 
Fermentation of the WS portion after simultaneous saccharification and isomerization ${ }^{7}$

Fermentation was performed on the WS portion after simultaneous saccharification and isomerization without agitation in the 7-ml glass bottle. The WS portion was provided with inoculum and nutrient broth to be prepared as the fermentation medium. The $\mathrm{pH}$ was adjusted to 5.0 using solid $\mathrm{Ca}(\mathrm{OH})_{2}$ and $\mathrm{HCl}$ solution, and the temperature was set at $30^{\circ} \mathrm{C}$.

Process schemes for ethanol production

Ethanol production from the WS portion and the residue was performed as shown in Figure 1, which shows schemes 1-5 for comparison. Schemes 2 and 4 were processes with fractionation, and schemes 3 and 5 were processes with integration. Schemes 4 and 5 were modified processes of schemes 2 and 3 respectively, where cellulase was added prior to fermentation.

Scheme 1 was a process without fractionation and integration. In this scheme, a mixture of the WS portion and the residue was processed. Xylooligosaccharides (XO) and cellulose were the main substrates in the WS portion and the residue respectively. The mixture was divided into two parts; one part for the ethanol production from xylooligosaccharides (XO) in the WS portion (scheme 1A), and the other part for the ethanol production from cellulose in the residue (scheme 1B).

For scheme 1A, simultaneous saccharification and isomerization was performed for 96h by adding $\beta$-xylosidase and xylose isomerase to the mixture at $\mathrm{pH} 6.0$ and $50^{\circ} \mathrm{C}$, where xylooligosaccharides (XO) were converted into xylulose (XL). Then fermentation of the WS portion after simultaneous saccharification and isomerization was performed for $48 \mathrm{~h}$ by adding $S$. cerevisiae in the form of the fermentation medium at $\mathrm{pH} 5.0$ and $30^{\circ} \mathrm{C}$, where xylulose (XL) was converted into ethanol (EtOH). 
For scheme 1B, SSF was performed for $72 \mathrm{~h}$ by adding cellulase and $S$. cerevisiae to the mixture at pH 5.0 and $30^{\circ} \mathrm{C}$ or $40^{\circ} \mathrm{C}$, where cellulose was converted into ethanol (EtOH).

Scheme 2 was a process with fractionation and without integration. In this scheme, the WS portion and the residue were fractionated to be processed separately. Ethanol production from xylooligosaccharides (XO) in the WS portion (scheme 2A), and from cellulose in the residue (scheme 2B) were performed in the same way as in scheme $1 \mathrm{~A}$ and Scheme $1 \mathrm{~B}$ respectively.

Scheme 3 was a process with integration and without fractionation. In this scheme, a mixture of the WS portion and the residue was processed. In the mixture of the WS portion and the residue, xylooligosaccharides (XO) in the WS portion were converted into ethanol via xylulose by simultaneous saccharification and isomerization followed by fermentation. Cellulose in the residue was converted into ethanol (EtOH) by SSF at the same time.

Simultaneous saccharification and isomerization was performed for 96h by adding $\beta$-xylosidase and xylose isomerase to the mixture of the WS portion and the residue at $\mathrm{pH} 6.0$ and $50^{\circ} \mathrm{C}$, where xylooligosaccharides (XO) were converted into xylulose (XL) in the WS portion. Then, fermentation of the WS portion after simultaneous saccharification and isomerization together with SSF of the residue were performed for $96 \mathrm{~h}$ by adding cellulase and S. cerevisiae in the form of the fermentation medium at $\mathrm{pH} 5.0$ and $30^{\circ} \mathrm{C}$. Xylulose (XL) in the WS portion and cellulose in the residue were converted into ethanol $(\mathrm{EtOH})$.

Scheme 4 was a modification of scheme 2 . In this scheme, the WS portion and the residue were fractionated for separate processing. Ethanol was produced from xylooligosaccharides (XO) in the WS portion (scheme 4A) and from cellulose in the residue (scheme 4B). For the WS portion (scheme 4A), ethanol production was achieved in the same way as in scheme 2A.

For the residue (scheme 4B), enzymatic saccharification prior to fermentation was performed for $96 \mathrm{~h}$ by adding cellulase to the residue at $\mathrm{pH} 6.0$ and $50^{\circ} \mathrm{C}$, where cellulose was partly converted into glucose (G). Then, SSF was performed for $72 \mathrm{~h}$ by adding S. cerevisiae to the residue at 
$\mathrm{pH} 5.0$ and $30^{\circ} \mathrm{C}$ or $40^{\circ} \mathrm{C}$, where residual cellulose and glucose were converted into ethanol (EtOH).

Scheme 5 was a modified process of scheme 3. In this scheme, a mixture of the WS portion and the residue was processed as well as in scheme 3 . In scheme 5, simultaneous saccharification and isomerization in the WS portion together with saccharification of the residue with cellulase prior to fermentation were performed for $96 \mathrm{~h}$ by adding $\beta$-xylosidase, xylose isomerase and cellulase to the mixture of the WS portion and the residue at $\mathrm{pH} 6.0$ and $50^{\circ} \mathrm{C}$. Xylooligosaccharides (XO) were converted into xylulose (XL) in the WS portion and cellulose was partly converted into glucose (G) in the residue. Then, fermentation of the WS portion after simultaneous saccharification and isomerization together with SSF of the residue were performed for $96 \mathrm{~h}$ by adding $S$. cerevisiae in the form of the fermentation medium at $\mathrm{pH} 5.0$ and $30^{\circ} \mathrm{C}$. Xylulose (XL) in the WS portion and, residual cellulose and glucose (G) in the residue were converted into ethanol (EtOH).

Analytical methods

Glucose, xylose, xylulose and ethanol were analyzed by HPLC (LC-10A, Shimadzu, Kyoto, Japan) with a refractive index detector (RID-10A, Shimadzu, Kyoto, Japan). A Shodex SUGAR KS-801 column (Showa Denko K. K., Tokyo, Japan) was used in a column oven set at $80^{\circ} \mathrm{C}$ with distilled water as the mobile phase at a flow rate of $1 \mathrm{ml} \mathrm{min}^{-1}$. Xylooligosaccharides larger than xylotriose in the WS portion and cellulose content in the residue were quantified based on the amount of xylose after sulfuric acid hydrolysis using an Aminex HPX-87H column. ${ }^{6}$

Results and discussion

HCW treatment 
With the HCW treatment of Japanese beech at $240^{\circ} \mathrm{C}$ for $90 \mathrm{~s}, 47.8 \%$ of the raw material was solubilized to be recovered as the WS portion. Xylose, xylobiose, xylotriose and larger xylooligosaccharides were recovered in the WS portion at $2.50 \mathrm{~g} \mathrm{~L}^{-1}, 1.30 \mathrm{~g} \mathrm{~L}^{-1}, 0.95 \mathrm{~g} \mathrm{~L}^{-1}$ and $4.63 \mathrm{~g}$ $\mathrm{L}^{-1}$. Glucose was also recovered at $0.34 \mathrm{~g} \mathrm{~L}^{-1}$ and cellooligosaccharides at less than $0.10 \mathrm{~g} \mathrm{~L}^{-1}$. Cellulose content in the residue was $82.6 \%$.

Ethanol production without fractionation and integration (scheme 1)

In scheme 1, a mixture of the WS portion and the residue was processed. Simultaneous saccharification and isomerization followed by fermentation was performed on the WS portion of one part of the mixture (scheme 1A), and SSF was performed on the residue of the other part (scheme 1B). Figure 2 shows the time course of the concentrations of glucose, xylulose, and ethanol during ethanol production from the mixture.

For scheme 1A, after $96 \mathrm{~h}$ of simultaneous saccharification and isomerization xylulose reached the maximal concentration of $0.44 \mathrm{~g} \mathrm{~L}^{-1}$ before it was partly consumed in the subsequent fermentation. Ethanol concentration reached $0.94 \mathrm{~g} \mathrm{~L}^{-1}$ after $48 \mathrm{~h}$ of fermentation. This value was more than $0.15 \mathrm{~g} \mathrm{~L}^{-1}$ which was potentially produced from the apparent consumed xylulose concentration of $0.30 \mathrm{~g} \mathrm{~L}^{-1}$ as in Fig. 2. This could be owing to the effect of integration of saccharification and isomerization as described in our previous study. Equilibrium reactions of both saccharification with $\beta$-xylosidase and isomerization with xylose isomerase were assumed to be involved in this process. Decreased xylulose concentration pulled the equilibrium reaction of isomerization toward xylulose, and a decrease in xylose concentration pulled the equilibrium reaction of saccharification toward xylose, resulting into more xylulose being produced to be consumed in the following fermentation. ${ }^{7}$

For scheme $1 \mathrm{~B}$, the results obtained at $30^{\circ} \mathrm{C}$ are shown and similar results were obtained at 
$40^{\circ} \mathrm{C}$. Ethanol was hardly produced during $72 \mathrm{~h}$ of SSF, although glucose concentration increased to as high as $6.05 \mathrm{~g} \mathrm{~L}^{-1}$. It was indicated that fermentation by $\mathrm{S}$. cerevisiae was severely inhibited and resulted in accumulation of glucose.

Ethanol production with fractionation and without integration (scheme 2)

In scheme 2, simultaneous saccharification and isomerization followed by fermentation was performed on the WS portion and SSF was performed separately on the residue. Figure 3 shows the time course of the concentrations of xylulose and ethanol during ethanol production from the WS portion (scheme 2A), and glucose and ethanol from the residue (scheme 2B).

For the WS portion (scheme 2A), the results obtained were similar to those in scheme $1 \mathrm{~A}$, where the ethanol concentration was higher than the xylulose concentration consumed during the fermentation. Ethanol produced was $0.92 \mathrm{~g} / \mathrm{L}$, which was almost equal to the value in scheme $1 \mathrm{~A}$.

For the residue (scheme 2B), the results obtained at $30^{\circ} \mathrm{C}$ are shown. Similar results were obtained at $40^{\circ} \mathrm{C}$. Ethanol reached the maximal concentration of $3.27 \mathrm{~g} \mathrm{~L}^{-1}$ at $48 \mathrm{~h}$.

The ethanol yield from the residue was $78 \%$ of the theoretical value of $4.21 \mathrm{~g} \mathrm{~L}^{-1}$. The SSF yield of $60 \%$ of the theoretical yield was reported from the washed solid fraction of pretreated poplar with HCW treatment at $240^{\circ} \mathrm{C}$ using a thermotolerant yeast. ${ }^{10}$ It was $55 \%$ from washed, pretreated yellow poplar sawdust with HCW treatment at $240^{\circ} \mathrm{C} .{ }^{11}$ Compared with these reports, the SSF yield in this study was higher. This was possibly because susceptibility of cellulose to cellulase in the residue was higher than that in the reported studies. There was no remarkable difference in the solubility of the raw material during the HCW treatment or in the cellulose content in the residue between this study and the reported studied. The solubility of the raw material was $47.8 \%$ and the cellulose content in the residue was $82.6 \%$ in this study, whereas the former was $40.0 \%{ }^{10}$ and $39.9 \%{ }^{11}$ and the latter was $73.6 \%{ }^{10}$ and $86.7 \%{ }^{11}$ in the previous reports. Therefore, the difference in the susceptibility of 
cellulose in the residue was attributed to the physicochemical properties such as crystallinity, porosity, and specific surface area. The difference in the heating profiles could have changed theses properties. In this study, the heating time until the inner temperature of the reactor $(5 \mathrm{ml})$ reached $240^{\circ} \mathrm{C}$ was $10 \mathrm{~s}$, whereas in the earlier studies, the heating time until the inner temperature of the reactor $\left(2 \mathrm{~L}^{10}\right.$ and 500 $\mathrm{ml},{ }^{11}$ ) reached $240^{\circ} \mathrm{C}$ was $70-75 \min ^{10}$ and $66 \mathrm{~min},{ }^{11}$ respectively.'

As shown in scheme 1 and Scheme 2, the fermentation was severely inhibited during SSF in the mixture of the WS portion and the residue (scheme 1B), although SSF of the residue proceeded successfully proceeded (scheme 2B). The fermentation was probably inhibited by the compounds contained in the WS portion. Nevertheless, on the other hand, the fermentation after simultaneous saccharification and isomerization appeared to proceed without inhibition either for the mixture of the WS portion and the residue (scheme 1A) and for the WS portion (scheme 2A). This suggested that the inhibition of the fermentation after simultaneous saccharification and isomerization was somehow mitigated. The detailed mechanism of this effect was not investigated because that was not the main concern in this study, but it was presumed that the preceding saccharification and isomerization were possibly related to this effect. For example, saccharification with $\beta$-xylosidase and/or isomerization with xylose isomerase may have caused compositional or physicochemical changes in the WS portion.

Ethanol production with integration and without fractionation (scheme 3)

In scheme 3, a mixture of the WS portion and the residue was processed. Simultaneous saccharification and isomerization followed by fermentation on the WS portion together with SSF on the residue were performed. Figure 4 shows the time course of the concentrations of glucose, xylulose, and ethanol during ethanol production from the mixture.

After $24 \mathrm{~h}$ of fermentation, the ethanol concentration reached $3.61 \mathrm{~g} \mathrm{~L}^{-1}$, then decreased 
gradually to be finally depleted. Ethanol was presumably reassimilated by Saccharomyces cerevisiae to be utilized as a carbon source. No particular inhibition of the fermentation in the mixture of the WS portion and the residue was found in this integrated process. This is in contrast to the results obtained in the process without integration (scheme 1B), suggesting that integration was effective in ethanol production possibly due to the reason mentioned above.

Modification of operation pattern (schemes 4, 5)

To further improve the ethanol production, the operation pattern was modified by adding cellulase prior to SSF of the residue to be subjected to the processes in scheme 4B and 5 . In scheme 4B, cellulase was added at $0 \mathrm{~h}$ prior to SSF, which was initiated by adding S. cerevisiae at $96 \mathrm{~h}$. The results obtained at $30^{\circ} \mathrm{C}$ are shown in Fig. 5. Similar results were obtained at $40^{\circ} \mathrm{C}$. Glucose concentration increased sharply within the first $24 \mathrm{~h}$ of enzymatic saccharification with cellulase and reached $7.66 \mathrm{~g} \mathrm{~L}^{-1}$ at the beginning of SSF, suggesting that cellulose contained in the residue at $8.26 \mathrm{~g}$ $\mathrm{L}^{-1}$ was almost completely converted into glucose during $96 \mathrm{~h}$ of saccharification with cellulase. After $12 \mathrm{~h}$ of the SSF that followed, glucose and residual cellulose were completely converted into ethanol at $4.36 \mathrm{~g} \mathrm{~L}^{-1}$, and decreased gradually. The ethanol concentration produced in scheme 4B was higher than that in scheme 2B. This was possibly because cell mass growth was enhanced in the early stage of the SSF due to the higher initial glucose concentration, which caused higher ethanol productivity. ${ }^{12}$

In scheme 5 , cellulase was added in combination with $\beta$-xylosidase and xylose isomerase at 0 h prior to SSF, which was initiated by adding S. cerevisiae at $96 \mathrm{~h}$. The results obtained at $30^{\circ} \mathrm{C}$ are shown in Fig. 6. The results were similar to those from scheme 4B, in that glucose concentration increased during the enzymatic saccharification with cellulase to reach $4.25 \mathrm{~g} \mathrm{~L}^{-1}$ at the beginning of SSF, suggesting that $51 \%$ of the cellulose contained in the residue was converted into glucose. This value was lower than that obtained in scheme 4B. This was probably because of the inhibitory effect of 
the compounds in the WS portion on cellulase, and loss of glucose by isomerization of glucose into fructose. After $24 \mathrm{~h}$ of the SSF that followed the glucose concentration decreased and the ethanol concentration increased to reach $4.81 \mathrm{~g} \mathrm{~L}^{-1}$, and then decreased gradually. The ethanol concentration produced in scheme 5 was higher than that in scheme 3, probably due to the same reason for scheme 4B.

Comparison of ethanol yields for process schemess

The ethanol yields for the different process schemes are compared in ethanol yields as in Table 1. The ethanol yield was defined as the produced ethanol concentration relative to the theoretical ethanol concentration of $9.00 \mathrm{~g} \mathrm{~L}^{-1}$. This assumes that the xylose and xylooligosaccharides initially present in the WS portion and the cellulose initially present in the residue were completely converted into ethanol.

The yields obtained in scheme 4 and Scheme 5 were approximately 12\%-13\% higher than those in scheme 2 and scheme 3, respectively as shown in Figs. 5 and 6. This result indicates that modifying the process by as adding cellulase prior to fermentation was effective in improving the ethanol yield.

Although the highest yield was obtained in scheme 4, the yield in scheme 5 was also comparable with that in scheme 4. It is suggested that an efficient ethanol production is possible without fractionation of the WS portion and the residue by integrating the processes for the WS portion and the residue.

From a practical viewpoint, fractionation by centrifugation and filtration is undesirable, where integration of different enzymatic and microbial processes is desirable. The results obtained in this study are thought to be useful in evaluating the process design of the ethanol production from the substrate hydrolysate after HCW treatment. 
Conclusions

Ethanol production from the mixture of the WS portion and the residue after the HCW treatment of Japanese beech without fractionation showed only slight loss in ethanol yield when integrating the processes for the WS portion and the residue. In the integrated process, the inhibitory effects of the compounds contained in the WS portion on fermentation were possibly mitigated. Ethanol yields were further improved in the integrated processes by adding cellulase prior to fermentation.

Acknowledgments

This work was supported by KAKENHI (19 6528), a Grant-in-Aid for Japan Society for the Promotion of Science (JSPS) Fellows. 
References

1. Chiang L-C, Gong C-S, Chen L-F, Tsao GT (1981) D-Xylulose fermentation to ethanol by Saccharomyces cerevisiae. Appl Environ Microbiol 42:284-289

2. Pérez JA, Ballesteros I, Ballesteros M, Sáez F, Negro MJ, Manzanares P (2008) Optimizing liquid hot water pretreatment conditions to enhance sugar recovery from wheat straw for fuel-ethanol production. Fuel 87: 3640-3647

3. Söderström J, Galbe M, Zacchi G (2005) Separate versus simultaneous saccharification and fermentation of two-step steam pretreated softwood for ethanol production. J Wood Chem Technol 25: $187-202$

4. Öhgren K, Bura R, Lesnicki G, Saddler J, Zacchi G (2007) A comparison between simultaneous saccharification and fermentation and separate hydrolysis and fermentation using steam-pretreated corn stover. Process Biochem 42: 834-839

5. Öhgren K, Vehmaanperä J, Siika-Aho M, Galbe M, Viikari L, Zacchi G (2007) High temperature enzymatic prehydrolysis prior to simultaneous saccharification and fermentation of steam pretreated corn stover for ethanol production. Enzym Microb Technol 40: 607-613

6. Nakata T, Miyafuji H, Saka S (2009) Enzymatic saccharification of the water-soluble portion after hot-compressed water treatment of Japanese beech with xylanase and $\beta$-xylosidase. J Wood Sci $55: 209-214$

7. Nakata T, Miyafuji H, Saka S (2009) Ethanol production with $\beta$-xylosidase, xylose isomerase and Saccharomyces cerevisiae from the water-soluble portion of Japanese beech after hot-compressed water treatment. J Wood Sci, doi: 10.1007/s10086-009-1033-5

8. Saka S, Ueno T (1999) Chemical conversion of various celluloses to glucose and its derivatives in supercritical water. Cellulose 6: 177-191

9. Ehara K, Saka S (2002) A comparative study on chemical conversion of cellulose between the 
batch-type and flow-type systems in supercritical water. Cellulose 9: 301-311

10. Weil J, Sarikaya A, Rau SL, Goetz J, Ladisch CM, Brewer M, Hendrickson R, Ladisch MR (1997) Pretreatment of yellow poplar sawdust by pressure cooking in water. Appl Biochem Biotechnol 68: 21-40

11. Negro MJ, Manzanares P, Ballesteros I, Olivia JM, Cabanas A, Ballesteros M (2003) Hydrothermal pretreatment conditions to enhance ethanol production from poplar biomass. Appl Biochem Biotechnol 105-108: 87-100

12. Chung IS, Lee YY (1985) Ethanol fermentation of crude acid hydrolyzate of cellulose using high-level yeast inocula. Biotechnol Bioeng 27: 308-315 
Scheme 1

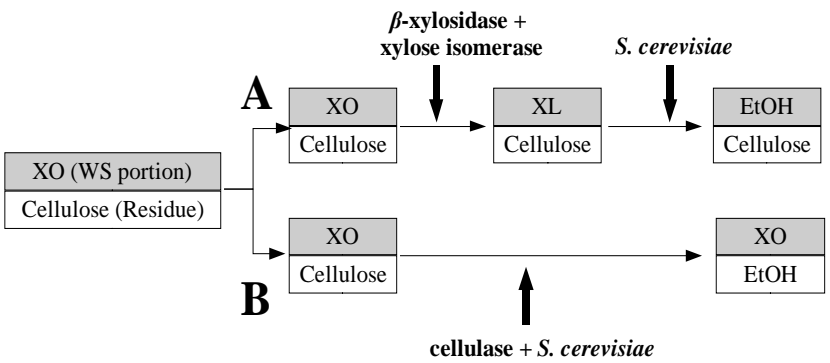

Scheme 2

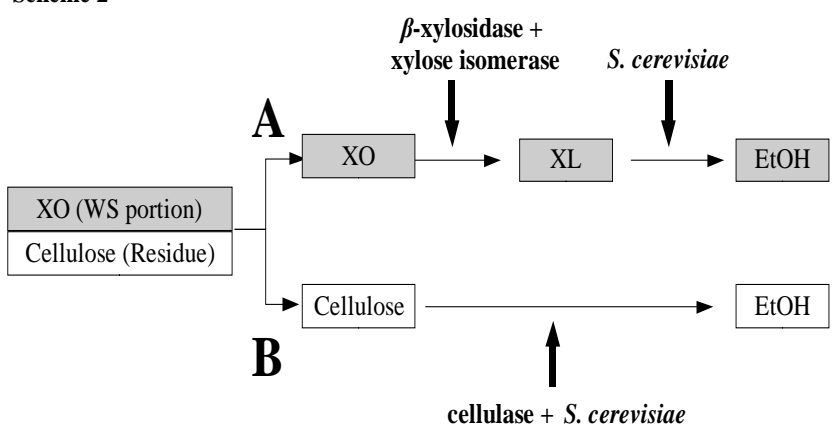

Scheme 3

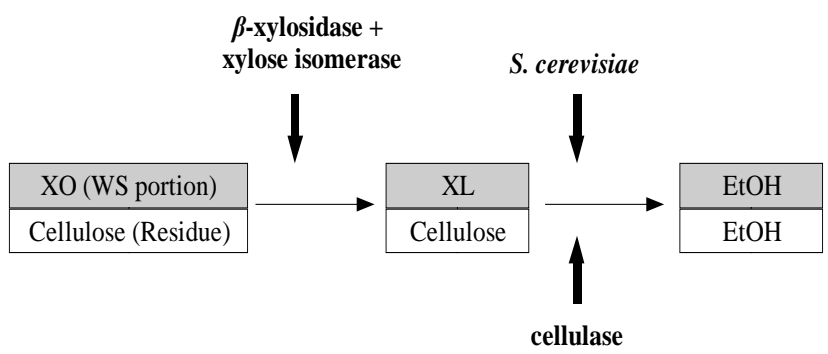

Scheme 4

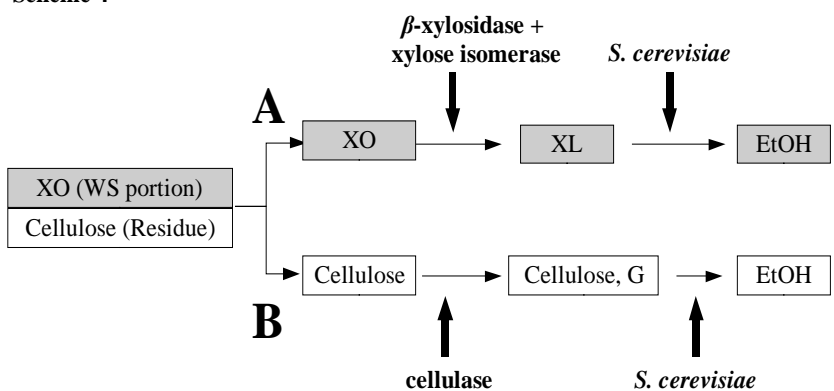

Scheme 5

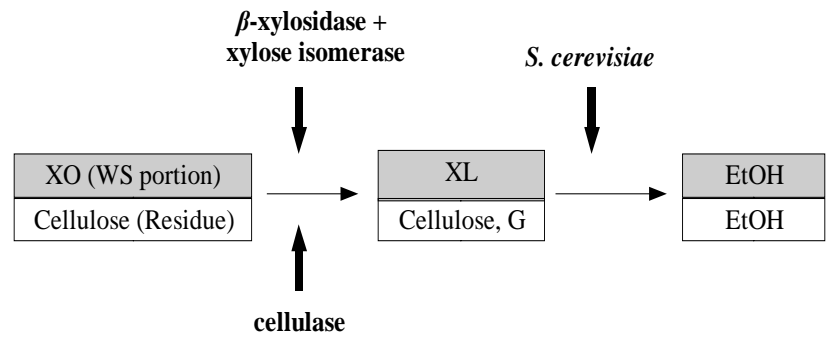

Fig. 1. Process schemes for ethanol production from the water-soluble (WS) portion and the residue obtained after the hot-compressed water (HCW) treatment of Japanese beech.

XO, Xyloologosaccharides; XL, xylulose; EtOH, ethanol 


\section{Scheme 1A}

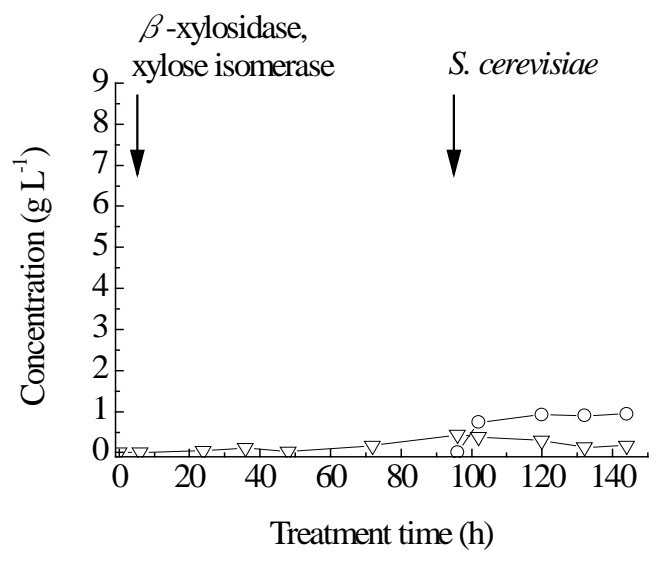

Scheme 1B

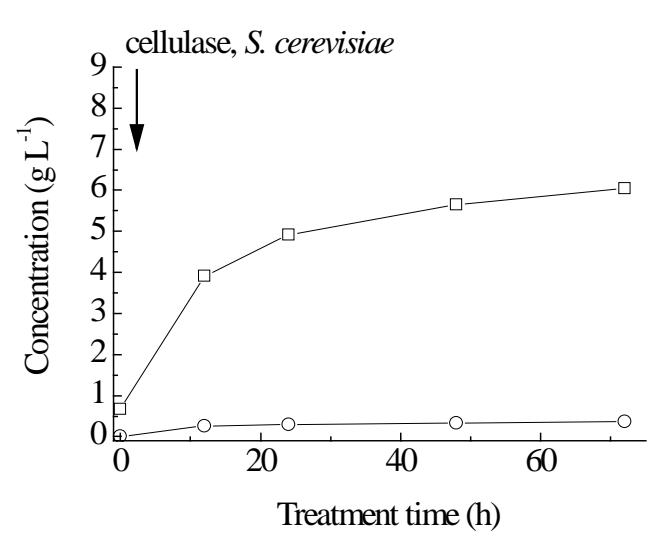

Fig. 2. Time course of the concentrations of glucose, xylulose, and ethanol during the process of scheme 1. Arrows show time of addition of process agents. Circles, ethanol; squares, glucose; triangles, xylulose 


\section{Scheme 2A}

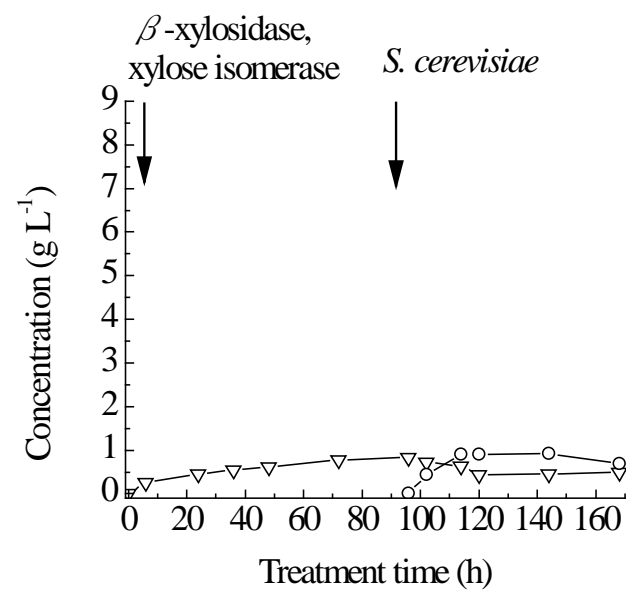

\section{Scheme 2B}

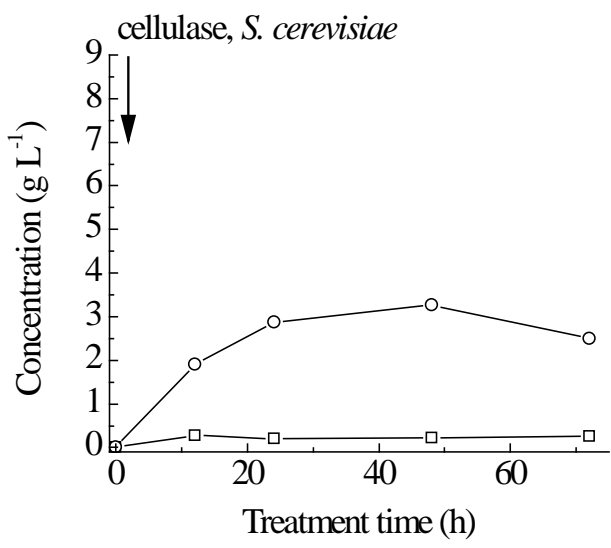

Fig. 3. Time course of the concentrations of glucose, xylulose, and ethanol during the process of scheme 2. Arrows show time of addition of process agents. Circles, ethanol; squares, glucose; triangles, xylulose 
$\beta$-xylosidase,

xylose isomerase cellulase, S. cerevisiae

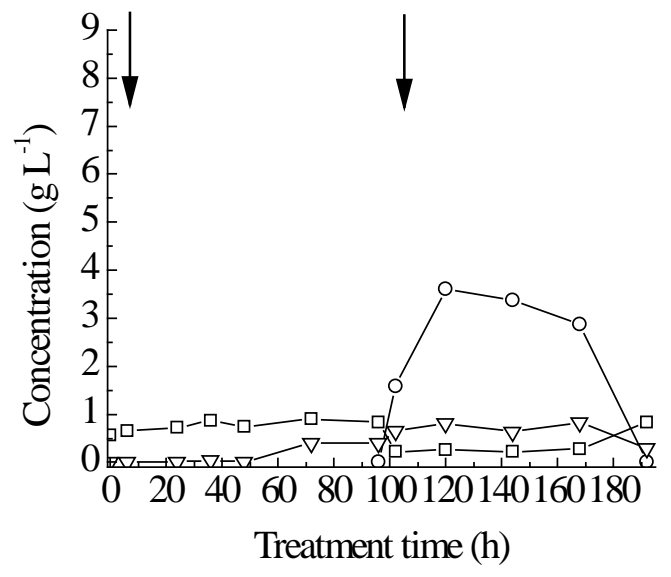

Fig. 4. Time course of the concentrations of glucose, xylulose, and ethanol during the process of scheme 3. Arrows show time of addition of process agents. Circles, ethanol; squares, glucose; triangles, xylulose 


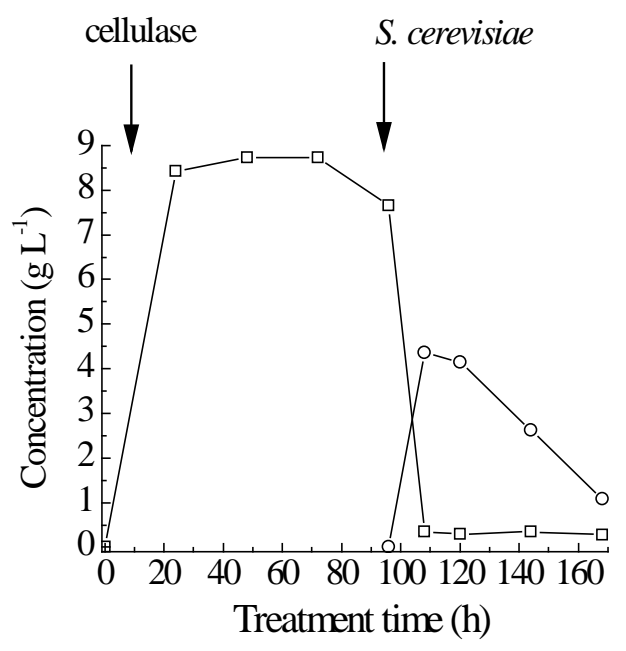

Fig. 5. Time course of the concentrations of glucose, xylulose, and ethanol during the process of scheme 4B. Arrows show time of addition of process agents. Circles, ethanol; squares, glucose 


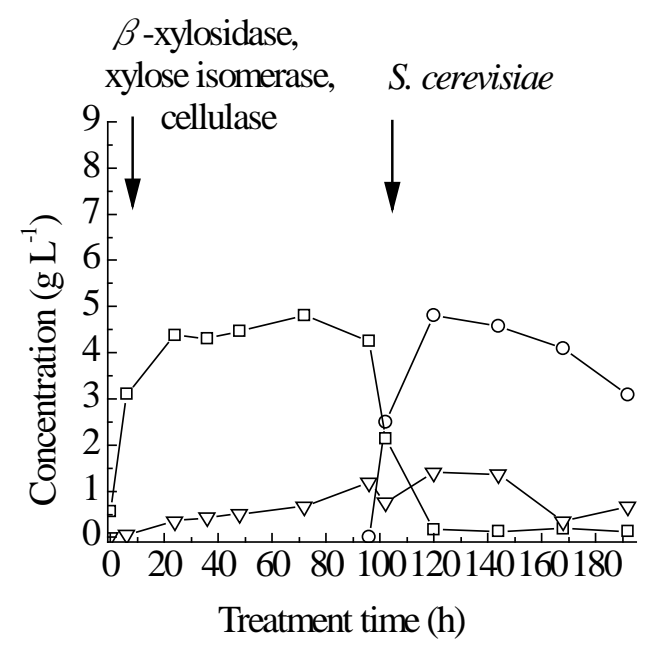

Fig. 6. Time course of the concentrations of glucose, xylulose, and ethanol during the process of scheme 5. Arrows show time of addition of process agents. Circles, ethanol; squares, glucose; triangles, xylulose 
Table 1 Ethanol yields from each of the schemes shown in Fig. 1.

\begin{tabular}{cccc}
\hline \multicolumn{2}{c}{ Scheme } & $\begin{array}{c}\text { Ethanol produced } \\
(\mathrm{g} / \mathrm{L})\end{array}$ & $\begin{array}{c}\text { Ethanol yield } \\
(\%)^{\text {a }}\end{array}$ \\
\hline Scheme 1 & $\mathbf{A}+\mathbf{B}$ & 1.30 & 14.4 \\
& $\mathbf{A}$ & 0.94 & - \\
& $\mathbf{B}$ & 0.36 & - \\
Scheme 2 & $\mathbf{A}+\mathbf{B}$ & 4.19 & 46.6 \\
& $\mathbf{A}$ & 0.92 & - \\
& $\mathbf{B}$ & 3.27 & - \\
Scheme 3 & & 3.61 & 40.1 \\
Scheme 4 & $\mathbf{A}+\mathbf{B}$ & 5.28 & 58.7 \\
& $\mathbf{A}$ & 0.92 & - \\
& $\mathbf{B}$ & 4.36 & - \\
Scheme 5 & & 4.81 & 53.4 \\
\hline
\end{tabular}

a Yield based on theoretical ethanol concentration from xylose and xylooligosaccharides in the water-soluble portion and cellulose in the residue 